\title{
Topical application of nucleotides increase lysozyme levels in tears
}

\author{
Assumpta Peral' \\ Patricia Loma ${ }^{2}$ \\ Benjamin Yerxa ${ }^{3}$ \\ Jesús Pintor ${ }^{2}$ \\ 'Departamento de Óptica II \\ (Optometría y Visión), Escuela \\ Universitaria de Óptica, Universidad \\ Complutense de Madrid, Madrid, \\ Spain; ${ }^{2}$ Departamento de Bioquímica \\ y Biología Molecular IV, Escuela \\ Universitaria de Óptica, Universidad \\ Complutense de Madrid, Madrid, \\ Spain; ${ }^{3}$ Inspire Pharmaceuticals, Inc. \\ Durham, North Carolina, USA
}

\begin{abstract}
The present work studies the effects of topical application of nucleotides on rabbit tear lysozyme levels. Lysozyme values were determined by the diffusion in Agar method described by van Bijsterveld in 1974, and the protein amount was obtained by measuring the inhibitory halos around a Whatman $\mathrm{n}^{\circ} 1$ paper disc of $5 \mathrm{~mm}$ in diameter. The tested nucleotides were UTP, $\mathrm{Ap}_{4} \mathrm{~A}$ and $\mathrm{Up}_{4} \mathrm{U}$. These compounds were topically instilled in a single-dose in one eye (with the contralateral eye as a control) and the lysozyme halos were measured along 5 hours. The obtained results showed an increase in the lysozyme concentrations of $67 \%, 93 \%$, and $119 \%$ for UTP, $\mathrm{Ap}_{4} \mathrm{~A}$, and $\mathrm{Up}_{4} \mathrm{U}$, respectively, over the basal levels of lysozyme. For this reason, we suggest these molecules as a potential treatment for the reinforcement of the tear film barrier against ocular infection.
\end{abstract}

Keywords: lysozyme, nucleotides, tear film, ocular infection, ocular protection, ocular surface

\section{Introduction}

Tear lysozyme is a high molecular weight, long chain glycolytic enzyme secreted by the lachrymal gland. Among the tear proteins identified, lysozyme constitutes around $20 \%-40 \%$ of the total tear protein (Farris 1985) and its concentration in the tear film is higher than in any other fluid of the body (Fleming 1922). This protein has the capacity to dissolve Gram-negative bacteria walls by the enzymatic digestion of mucopolysaccharides (Milder 1987). Due to this bactericidal action, lysozyme has been considered as one of the essential elements of the protective tear film barrier against ocular infection (Mackie and Seal 1976).

The importance of this lachrymal component has contributed to develop methods for its detection and measurement, as well as to correlate its concentration with ocular pathologies. Several studies have shown a decrease in the concentration of lysozyme in patients with keratoconjunctivitis sicca (van Bijsterveld 1969; Mackie 1984; Montero 1990), suggesting that a drop off in tear lysozyme levels may constitute an important parameter to detect a malfunctioning lachrymal gland (Klaeger 1999).

Recently, the presence of a new family of compounds in the tear film have been described: the diadenosine polyphosphates (Pintor, Carracedo et al 2002). These naturally occurring dinucleotide compounds exhibit both intracellular and extracellular physiological actions, these including vasoactive properties, neuromodulatory regulation of neurotransmitter release or intracellular modulation of ion channels (McLennan 2000; Hoyle 2002). Formed by two adenosine molecules joined by a variable phosphate chain, they are abbreviated as ApnA ( $n=2-7$, where $n$ describes the number of phosphates). The activity of these nucleotides on ocular tissues is being investigated, and it is known that they act through $\mathrm{P} 2$ receptors to modulate intraocular pressure in rabbits (Pintor, Peral, Peláez et al 2002); $\mathrm{Ap}_{4} \mathrm{~A}$ and UTP improve the rate of wound healing in the cornea of New Zealand white rabbits (Pintor, Bautista et al 2004) and also, Ap $A, A_{5} A$, and 
$\mathrm{Ap}_{6} \mathrm{~A}$, can stimulate tear secretion after single-dose topical application in rabbits (Pintor, Peral, Hoyle et al 2002).

In order to investigate the physiological role of nucleotides onto the tear film, lysozyme levels in New Zealand white rabbits tears have been measured after a topical application of the mentioned substances. The methodological approach used to get the lysozyme levels has been the agar diffusion method described by van Bijsterveld (1974). The analysis of the data suggests an increase in tear lysozyme levels with the application of the tested nucleotides.

\section{Experimental procedures}

\section{Animals}

Twelve male New Zealand white rabbits from Granja Cunicula San Bernardo (Navarra, Spain) weighing 2.0-2.5 kg were kept in individual cages with free access to food and water and subjected to regular cycles of light and dark (12 hours each). The New Zealand white rabbits were 6 months old and the slit lamp exam evidenced no ocular pathology or alteration that could affect the tear secretion. All the experiments were performed according to Association for Research in Vision and Ophthalmology (ARVO) Statement for the Use of Animals in Ophthalmic and Vision Research and in accordance with the European Communities Council Directive (86/609/EEC).

\section{Compounds}

Three nucleotides were tested along this work: UTP from Amersham Biosciences, Inc., (Piscataway, $\mathrm{NJ}$ ); $\mathrm{Ap}_{4} \mathrm{~A}$ from Sigma Chemical (St Louis, MO); $\mathrm{Up}_{4} \mathrm{U}$ (diquafosol or formerly INS365) kindly provided by Inspire Pharmaceuticals (Durham, NC, USA). The P2 antagonists employed were pyridoxalphosphate-6-azophenyl-2', 4'-disulfonic acid (PPADS), suramin and reactive blue-2 (RB-2) were purchased from Sigma/RBI (Natick MA).

For single dose experiments, all the nucleotides were applied in a concentration of $100 \mu \mathrm{M}$ in a volume of $10 \mu \mathrm{L}$ in the tested eye. The contralateral eye was instilled with $10 \mu \mathrm{L}$ saline $0.9 \%$. The $\mathrm{P} 2$ receptor antagonists PPADS, suramin and RB-2 were instilled in concentrations of $100 \mu \mathrm{M}(10 \mu \mathrm{L})$, $30 \mathrm{~min}$ before the application of any of the nucleotides.

The UTP, $A_{4} A$ and $\mathrm{Up}_{4} \mathrm{U}$ nucleotides were tested twice in the whole sample ( $\mathrm{n}=24$ each agonist). The P2 receptor antagonists were experienced once for each agonist in the whole sample ( $\mathrm{n}=12$ for each agonist).

\section{Diffusion in agar}

The Diffusion in agar method was employed to measure the lysozyme levels in rabbit tears. Callibration curves as well as all the lysozyme measurements were performed as indicated by van Bijsterveld (1974) and Mackie and Seal (1976). Briefly, the protein amount was obtained by measuring the inhibitory halos around a Whatman $\mathrm{n}^{\circ} 1$ paper disc of $5 \mathrm{~mm}$ in diameter. The paper discs were placed with clamps in the upper bulbar conjunctiva to avoid mucus strands. When the tears soaked the discs; they were removed and put on Petri dishes with Agar medium where Micrococus lisodeikticus was grown. The petri dishes were then incubated at $37{ }^{\circ} \mathrm{C}$ for 24 hours and finally the zones of lysis of Micrococus lisodeikticus were measured. Lysozyme standard curves for its quantification was performed with known concentrations of HEL (Hen Egg Lysozyme). For the mentioned curve, the $5 \mathrm{~mm}$ paper discs were weighed before and after being soaked by rabbit tears in order to estimate the equivalent volume of lysozyme solution to apply on the calibration paper discs. The difference in weight was the equivalent to $5 \mu \mathrm{L}$ of lysozyme solution, so that volume was applied to estimate the standard curve. Concentrations between $0.1 \mathrm{mg} / \mathrm{ml}$ and $1.0 \mathrm{mg} / \mathrm{ml}$ of standard hen lysozyme were applied on the discs in a final volume of $5 \mu$.

After two control measurements, $10 \mu \mathrm{L}$ of the studied compound was topically instilled in one eye (taking the contralateral eye as a control), and the tear samples were collected every hour for five hours. For measuring the diameter of the halos, petri dishes were scanned and analyzed by the computer program Imagej (v.1.37, NIH, USA). Briefly, scanned images of the inhibition halos were transformed into 8-bit black and white images and further transformed into a binary image prior to the corresponding calculation. With this standardized method, errors regarding borderlines, penumbra and other possible problems were minimized.

\section{Statistical analysis}

The lysozyme values presented are the means \pm S.D. of the experiments performed. Data were analyzed using the paired t-test and significance was set at $\mathrm{p}<0.05$.

\section{Results}

To determine whether these nucleotides were able to modify rabbit tear lysozyme levels at intervals after the nucleotide topical application, single doses of UTP, $\mathrm{Ap}_{4} \mathrm{~A}, \mathrm{Up}_{4} \mathrm{U}$ were applied at $100 \mu \mathrm{M}$ (at a final volume of $10 \mu \mathrm{l}$ ) (Figure 1). The results for the time-course of the single-dose application compared with the basal curve for lysozyme is represented in Figure 2. This Figure illustrates the behavior of the mentioned substances over the tear protein levels. It is possible to see that all the three substances increase the concentration 
<smiles>O=c1ccn(C2OC(COP(=O)(O)OP(=O)(O)OP(=O)(O)O)[C@@H](O)C2O)c(=O)[nH]1</smiles>

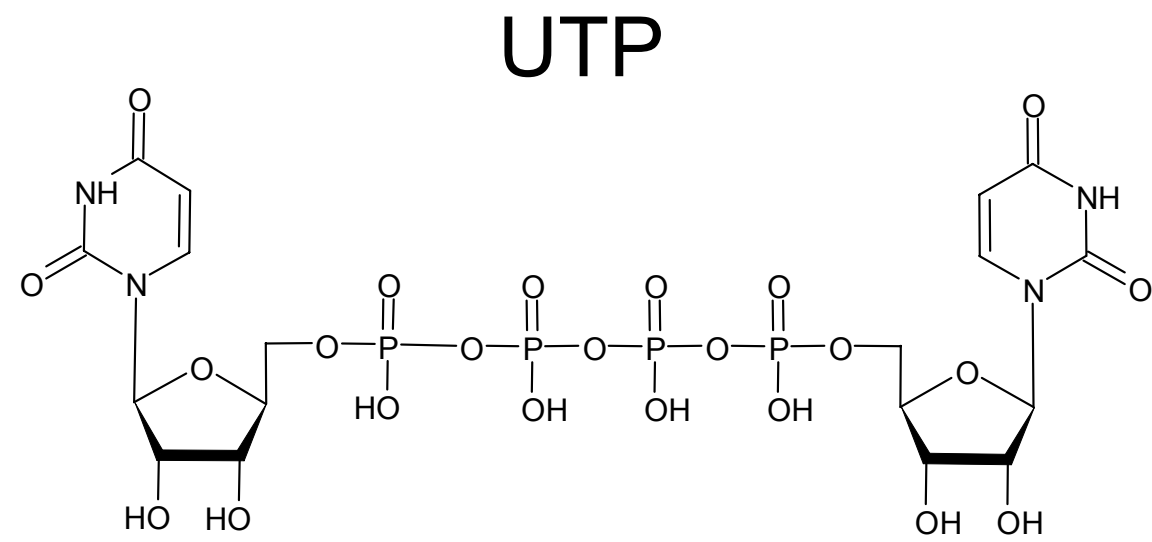

$\mathrm{Up}_{4} \mathrm{U}$

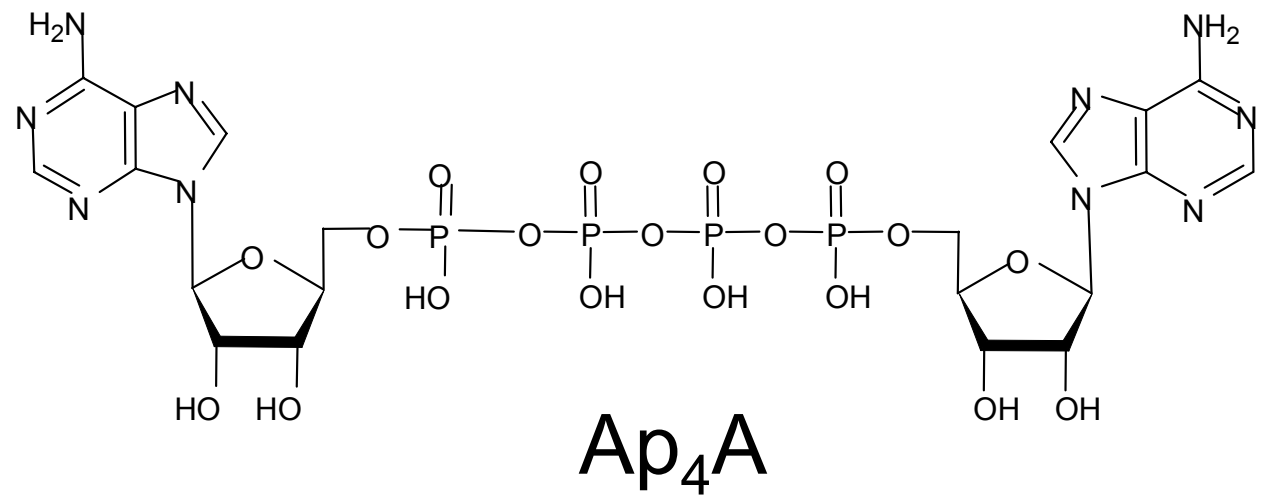

Figure I Structure of uridin triphoshate, UTP, diguanosine tetraphosphate $U_{P_{4}} U$, and diadenosine tetraphosphate, $A p_{4} A$.

of lysozyme in the rabbit tears, and that the maximal effect is obtained two hours after the instillation of the corresponding nucleotide. This effect remained for at least 3 more hours, then returned to basal levels (Figure 2).

A representative experiment showing the inhibitory halos around Whatman $\mathrm{n}^{\circ} 1$ paper discs in the moment of maximal effect is presented in Figure 3. These halos represent the zones of lysis of Micrococcus lysodeikticus due to the action of lysozyme. The first disc shows the basal diameter of lysis for a control rabbit (basal lysozyme concentration present in tears, Figure 3a). The others showed a maximal increased diameter of lysis due to the action of the different nucleotides on the tear lysozyme levels after their topical application (Figure 3a).

A representative value to compare effects among nucleotides can be obtained if we represent the mean of lysozyme concentration obtained for the period between 2 and 5 hours - plateau - for any of the substances versus basal 


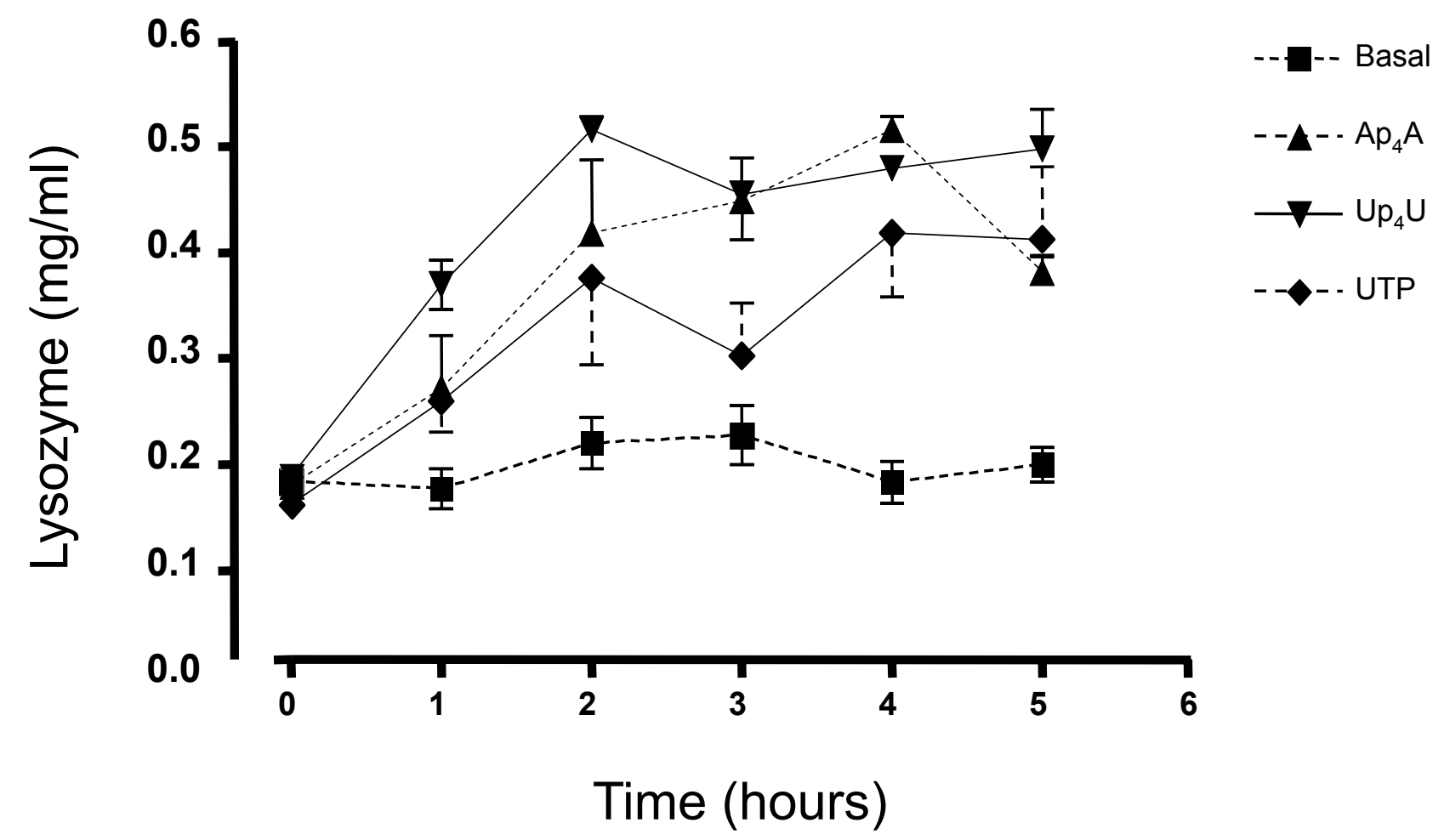

Figure 2 Time course of the increase of lysozyme concentrations after nucleotide instillation. The application of single doses of UTP, $U_{P_{4}} U$ and $A_{P_{4}} A$ produced a gradual increase in lysozyme levels reaching a maximal in two hours after the application of the corresponding nucleotide and remaining above the basal levels for at least three more hours. Values are the mean \pm SD of 4 independent experiments in triplicate.

concentration. As it is shown in Figure 3b, it is possible to see that the mean values for all the nucleotides showed a significant increase in lysozyme concentrations over the basal level. The increase in lysozyme concentration after the nucleotides application was $93 \%$ for $\mathrm{Ap}_{4} \mathrm{~A}, 119 \%$ for $\mathrm{Up}_{4} \mathrm{U}$ and $67 \%$ for UTP (Figure $3 b$ ).

The activity of the substances on tear lysozyme levels suggests the activation of $\mathrm{P} 2$ nucleotide receptors. To confirm this, the effects of three non-selective nucleotide receptor antagonists on lysozyme levels were studied: PPADS, suramin and RB-2. The antagonists were applied 30 minutes before the administration of nucleotides. The results shown in Figure 4 illustrate different behaviors on each compound.

Diadenosine tetraphosphate effect on lysozyme production was significantly reversed by the antagonist PPADS, returning the lysozyme concentration to control values. Neither of the other two, RB-2 or suramin was able to modify the effect triggered by $\mathrm{Ap}_{4} \mathrm{~A}$.

$\mathrm{Up}_{4} \mathrm{U}$ was antagonized by PPADS and suramin, the reduction being $42 \%$ and $52 \%$ for PPADS and suramin respectively. Concerning UTP, the $\mathrm{P} 2$ receptors antagonists did not antagonize this mononucleotide. Moreover, in the case of RB-2, there was a potentiation of UTP effect when compared with the effect of this nucleotide alone, showing an increase of almost $25 \%$ above the lysozyme concentration obtained when UTP is applied alone.

\section{Discussion}

This study shows for the first time the physiological effect of $\mathrm{Ap}_{4} \mathrm{~A}, \mathrm{Up}_{4} \mathrm{U}$ and UTP on the tear lysozyme levels in New Zealand white rabbits. All the tested nucleotides showed an increase in the lysozyme concentrations for a single-dose application, which was measurable for several hours after the topical application of the compounds.

Since lysozyme is one of the main proteins involved in the protective tear film barrier against ocular infection, together with lactoferrin, an increase in their levels may, in general, enhance the bactericidal action of tears, preserving the health of the ocular surface.

The presence of nucleotides and dinucleotides in the tear is suggesting their involvement in several relevant physiological processes of the ocular surface. We have added to the list of biological actions of nucleotides and dinucleotides the ability of these compounds to increase the tear concentrations of lysozyme. It is moreover relevant the fact of having important changes in the concentrations of this enzyme when $\mathrm{Up}_{4} \mathrm{U}$ or UTP are topically applied. These two nucleotides have not been described in tears but they 


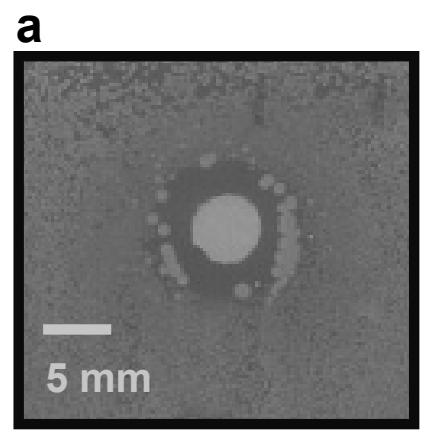

BASAL

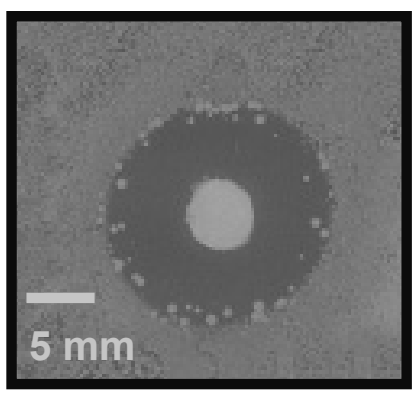

$100 \mu \mathrm{M}$ UTP

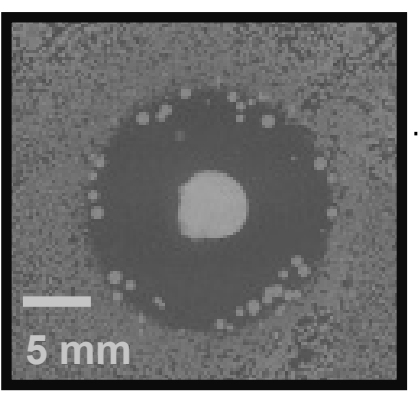

$100 \mu \mathrm{M} \mathrm{Ap}{ }_{4} \mathrm{~A}$

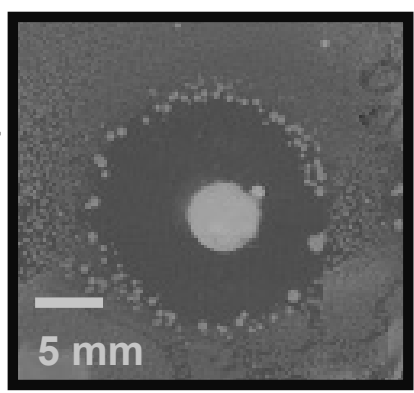

$100 \mu \mathrm{M} U p_{4} \mathrm{U}$

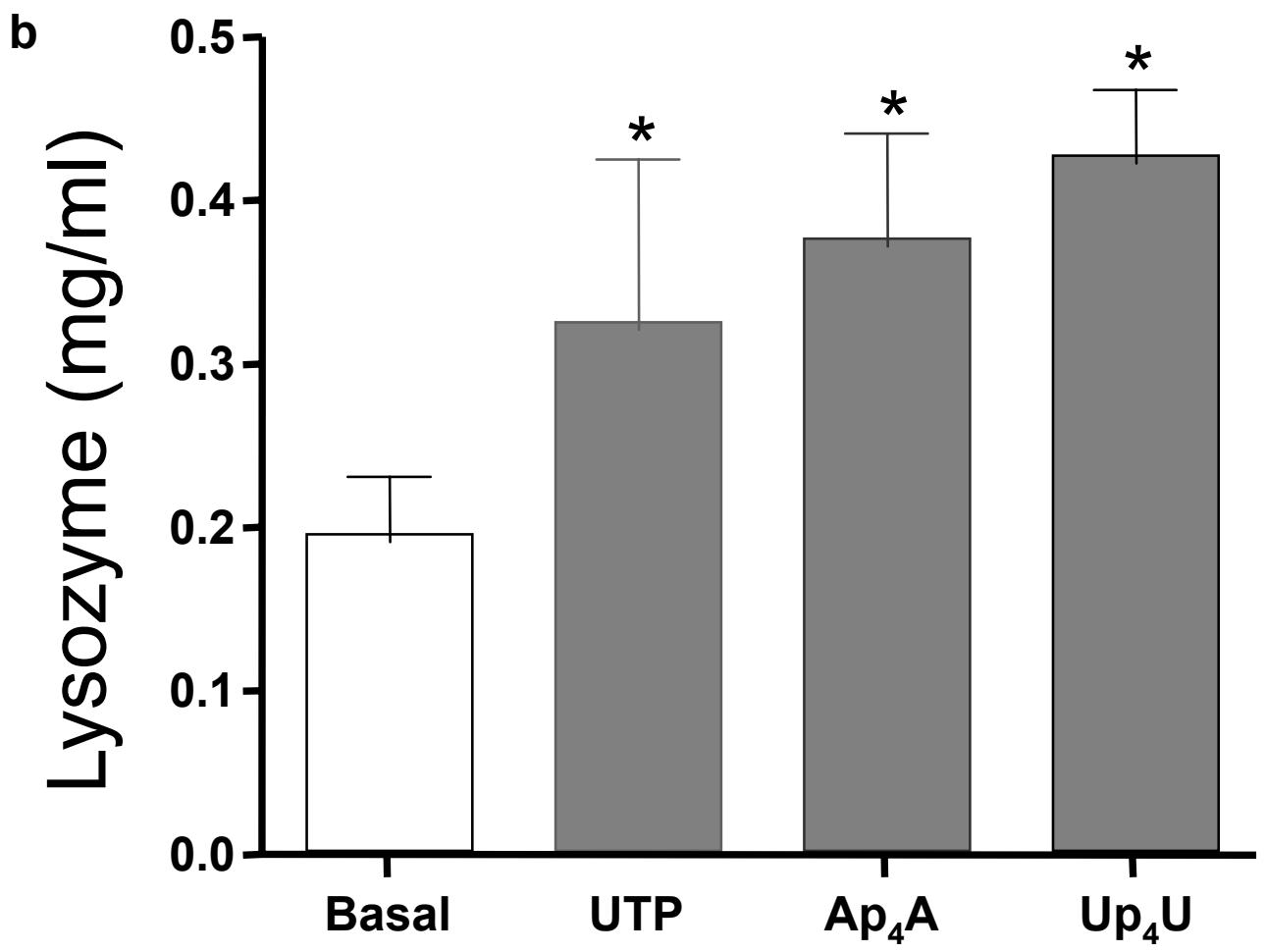

\section{Compounds}

Figure 3 Visualization and mean effect of nucleotides induced lysozyme concentration. (a) Agar diffusion experiments presenting the inhibitory halos obtained at the maximal effect of the nucleotides (all at $100 \mathrm{mM}$ ) which can be compared to basal lysozyme concentration (saline). (b) Comparative study of the mean effect of all the tested nucleotides (plateau) and the corresponding basal lysozyme concentration. The values represent mean \pm SD of 4 independent experiments in triplicate. $*_{\mathrm{p}}<0.001$.

behave similarly to $\mathrm{Ap}_{4} \mathrm{~A}$, suggesting that all may activate the same P2Y purinoceptor subtype. In this sense, the three tested nucleotides have been claimed to be quite selective for the $\mathrm{P}_{2} \mathrm{Y}_{2}$ purinergic receptors (Lazarowski et al 1995; Mundasad et al 2001). Nonetheless, the results obtained by means of the non-selective $\mathrm{P} 2$ receptor antagonists depict a different pattern depending on the tested nucleotide. In the case of $\mathrm{Ap}_{4} \mathrm{~A}$ the only effective antagonist was PPADS while in the case of $U p_{4} U$ apart from PPADS, suramin was also able to partially reverse the dinucleotide action. One may expect both nucleotides to stimulate the same receptor or group of receptors (see the similarities in the structure showed in Figure 1). Taking into account our results, it seems that $\mathrm{Ap}_{4} \mathrm{~A}$ and $\mathrm{Up}_{4} \mathrm{U}$ share some $\mathrm{P} 2 \mathrm{Y}$ receptor activation but in the case of $\mathrm{Up}_{4} \mathrm{U}$ it may activate more than one, since its increase in lysozyme is partially blocked by suramin while $\mathrm{Ap}_{4} \mathrm{~A}$ effect is not. This may be at least in part justified by the fact of the presence of several P2Y receptor in the lachrymal 


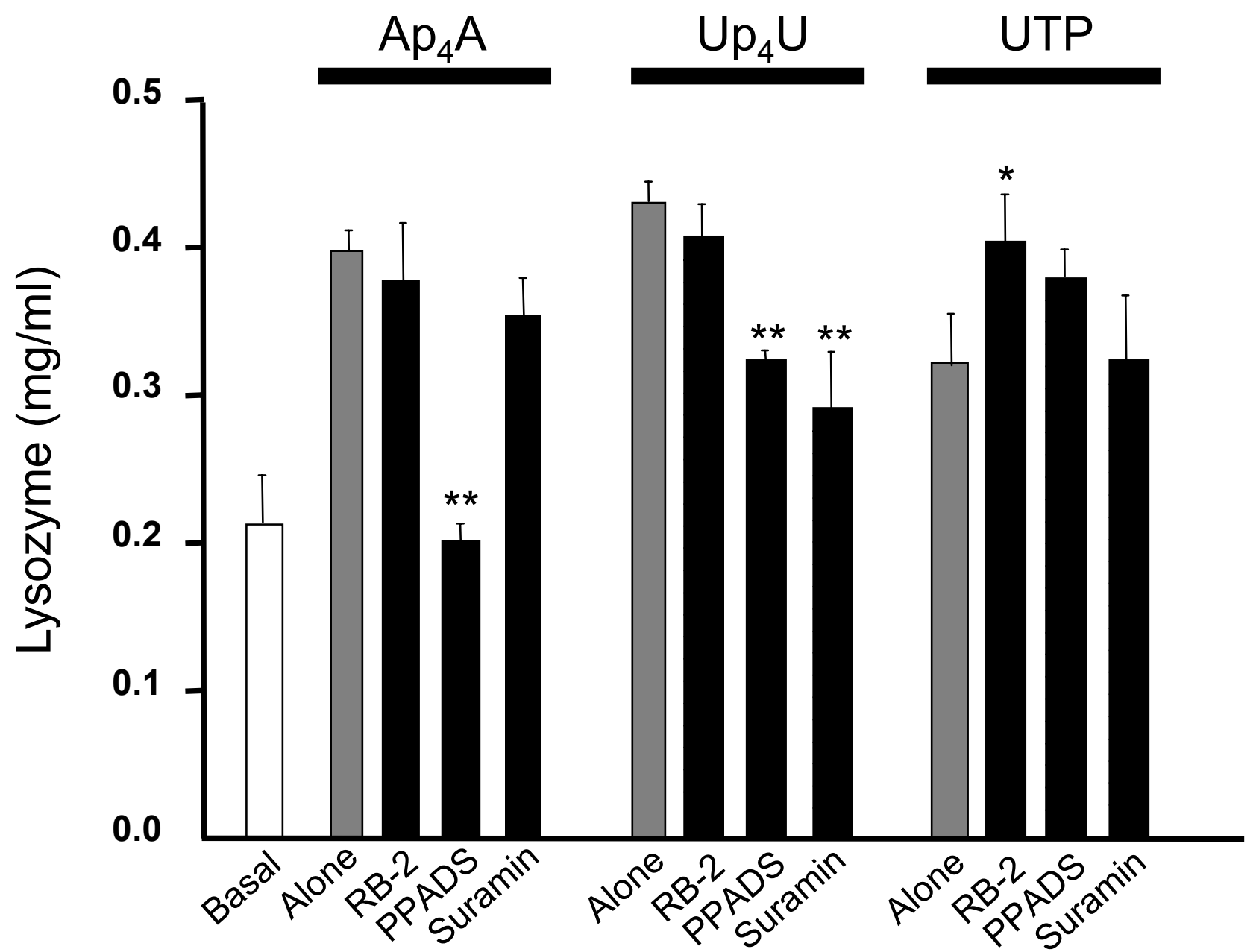

Figure 4 Effect of P2 receptor antagonists on the nucleotide-induced lysozyme concentration increase in tear. P2 receptor antagonists, assayed as described in methods, were tested in their ability to reverse the effects produced by the nucleotides. The values represent mean \pm SD of 3 independent experiments in triplicate. $*_{\mathrm{p}}<0.00 \mathrm{I}$ and $*^{*} \mathrm{p}<0.000 \mathrm{I}$.

gland and cornea (Cowlen et al 2003; Pintor, Bautista et al 2004; Pintor, Sanchez-Nogueiro et al 2004), and also by the fact that $\mathrm{Up}_{4} \mathrm{U}$ is known to activate at least $\mathrm{P} 2 \mathrm{Y}_{2}$ and $\mathrm{P} 2 \mathrm{Y}_{4}$ receptors (Brunschweiger and Muller 2006).

It is noteworthy the effect the antagonists of $\mathrm{P} 2$ receptors display on the UTP effect. Although one should expect that RB-2 might block the effect of UTP, the observed behavior of this antagonist shows the opposite effect. Reactive blue 2 has been described as a very potent inhibitor of all plasma membrane-bound NTPDases as reported by many authors (Mateo et al 1996, 1997). Since RB-2 inhibits ecto-enzymes and does not antagonize $\mathrm{P} 2 \mathrm{Y}$ receptors it is reasonable to see a potentiation of the UTP effect since it will not be degraded as fast as when it is applied alone.

Lysozyme levels are susceptible to present changes depending on various causes. For example, it has been described a decrease in lysozyme levels with age (Mackie and Seal 1976) as well as in other pathological states running with a drop off in tear secretion like keratoconjunctivitis sicca or sicca syndrome (Mackie and Seal 1984). Therefore, in these cases, it may be good to incorporate any of the indicated nucleotides as a new compound as a pharmacological treatment to reinforce the barrier against opportunistic infections.

Recently, apart from the bactericidal role, Tragoulias et al (2005) and Millar et al (2006) have suggested that lysozyme contributes to lower the surface tension of the tear film. In this case, an increase in lysozyme levels could contribute to stablizing the tear film, thus avoiding an excessive evaporation and the resulting problems on the ocular surface.

In summary, we have shown that the $\mathrm{P} 2 \mathrm{Y}$ receptor agonists, $\mathrm{Ap}_{4} \mathrm{~A}, \mathrm{Up}_{4} \mathrm{U}$ and UTP, are able to increase the tear concentrations of lysozyme. Due to the importance of this protein, these nucleotides may be used to fortify the tear film barrier by increasing a naturally occurring defender against some ocular surface infections. 


\section{References}

Brunschweiger A, Muller CE. 2006. P2 receptors activated by uracil nucleotides - an update. Current Medicinal Chemistry, 13:289-312.

Cowlen MS, Zhang VZ, Warnock L, et al. 2003. Localization of ocular P2Y2 receptor gene expression by in situ hybridization. Experimental Eye Research, 77:77-84.

Farris RL. 1985. Tear analysis in contact lens wearers. Trans Am Ophthalmol Soc, 83:501-45.

Fleming A. 1922. On a remarkable bacteriolytic element found in tissues and secretions. Roy Soc Proc B, 93:306-17.

Hoyle CHV, Hilderman R, Pintor JJ, et al. 2002. Diadenosine polyphosphates as extracellular signal molecules. Drug Dev Res, 52:260-73.

Klaeger AJ, Whitcher JP, Daniels TE. 1999. Tear lysozyme activity in frozen Schirmer strips and salivary gland biopsy as parameters of lacrimal gland function. Ocul Immunol Inflamm, 7:3-6.

Lazarowski ER, Watt WC, Stutts MJ, et al. 1995. Pharmacological selectivity of the cloned human P2U-purinoceptor: potent activation by diadenosine tetraphosphate. Br J Pharmacol, 116:1619-27.

Mackie IA, Seal DV. 1984. Diagnostic implications of tear protein profiles. Br J Ophthalmol, 68:321-4.

Mackie IA, Seal DV. 1976. Quantitative tear lysozyme assay in units of activity per microlitre. Br J Ophthalmol, 60:70-4.

Mateo J, Miras-Portugal MT, Rotllan P. 1997. Ecto-enzymatic hydrolysis of diadenosine polyphosphates by cultured adrenomedullary vascular endothelial cells. Am J Physiol, 273:C918-27.

Mateo J, Rotllan P, Miras-Portugal MT. 1996. Suramin - a powerful inhibitor of neural ecto-diadenosine polyphosphate hydrolase. $\mathrm{Br} J$ Pharmacol, 119:1-2.

McLennan AG. 2000. Dinucleoside polyphosphates - friends or foe? Pharmacol Ther, 87:73-89.

Milder B. 1987. The lacrimal apparatus. In: Moses RA, Hart WM eds. Adler's Physiology of the eye, 8th ed. St Louis, Mosby. P 15/35.
Millar TJ, Tragoulias ST, Anderton PJ, et al. 2006. The surface activity of purified ocular mucin at the air-liquid interface and interactions with meibomian lipids. Cornea, 25:91-100.

Montero J, Espejo F, Benárquez A, et al. 1990. Lisozima lagrimal en queratoconjuntivitis seca. Arch Soc Españ Oftalmol, 58:385-90.

Mundasad MV, Novack GD, Allgood VE, et al. 2001. Ocular safety of INS365 ophthalmic solution: a P2Y(2) agonist in healthy subjects. J Ocul Pharmacol Ther, 17:173-9.

Pintor J, Carracedo G, Alonso MC, et al. 2002. Presence of diadenosine polyphosphates in human tears. Pflügers Arch-Eur. J Physiol, 443:432-6.

Pintor J, Peral A, Peláez T, et al. 2002. Presence of diadenosine polyphosphates in the aqueous humour: Their effect on intraocular pressure. J Pharmacol Exp Ther, 304:342-8.

Pintor J, Peral A, Hoyle CHV, et al. 2002. Effects of diadenosine polyphosphates on tear secretion in New Zealand white rabbits. J Pharmacol Exp Ther, 300:1-7.

Pintor J, Bautista A, Carracedo G, et al. 2004. UTP and diadenosine tetraphosphate accelerate wound healing in the rabbit cornea. Ophthal Physiol Opt, 24:186-93.

Pintor J, Sanchez-Nogueiro J, Irazu M, et al. 2004. Immunolocalization of P2Y receptors in the rat eye. Purinergic Signalling, 1:83-90.

Tragoulias ST, Anderton PJ, Dennis GR, et al. 2005. Surface pressure measurements of human tears and individual tear film components indicate that proteins are major contributors to the surface pressure. Cornea, 24:189-200.

Van Bijsterveld OP. 1969. Diagnostic test in sicca syndrome. Arch Ophthalmol, 82:10-14.

Van Bijsterveld. OP. 1974. Standardization of the lysozyme test for a commercially available medium. Arch Ophthalmol, 91:432. 
